\title{
Fungi associated with Copaifera oblongifolia (Fabaceae) seeds: occurrence and possible effects on seed germination
}

\author{
Elio Gomes Fernandes ${ }^{1,2 *}$ (1), Henrique Maia Valério ${ }^{2}$ [D, Karen Luiza Rodrigues Duarte ${ }^{1}$ (D), Lauany Matos de \\ Novais Capuchinho ${ }^{2}$ (D) and Marcílio Fagundes ${ }^{1}$ (1)
}

Received: March 16, 2018

Accepted: August 29, 2018

\begin{abstract}
Copaifera oblongifolia is a recurrent plant species in degraded areas yet there is little information about its seed biology and interactions with fungi. The aims of this study were to identify the fungal community (endophytic and nonendophytic) associated with C. oblongifolia seeds and to test the effects of these different fungal species on germination. In general, germination of $C$. oblongifolia seeds was high (about $85 \%$ ), initiating four days after sowing and continuing for a total of 20 days. External asepsis with sodium hypochlorite did not influence germinability of $C$. oblongifolia. Seed infestation with Aspergillus niger, A. flavus, Mucor sp. and Rhizopus stolonifer did not affect the time required for germination, however, infection with A. flavus negatively affected germination percentage. Endophytic fungi were not isolated from $C$. oblongifolia seeds, suggesting that this species does not transmit endophytic fungi vertically. Therefore, C. oblongifolia can be classified in Class 3 with regard to the transmission and presence of endophytes.
\end{abstract}

Keywords: endophytic classification, endophytic fungi, saprophytic fungi, seed germination, seed-fungus interactions

Seed germination is one of the most critical phases of the life cycle of plants (Metivier 1986; Souza \& Fagundes 2014). Intrinsic seed traits (e.g., mass, hardness, age), and abiotic (e.g., light, temperature, humidity) and biotic (e.g., seeds predators and pathogens) factors may affect seed germination (Fagundes et al. 2011; Veloso et al. 2017). Among biotic factors, interactions between seeds and endophytic and non-endophytic fungi deserve special attention due to the widespread occurrence of these microorganisms and their beneficial, and sometimes harmful, effects on seeds germination (Harper 1977).
In general, both wild and cultivated plants are colonized by a high diversity of microorganisms, which can be found either on their outer surface or in their internal tissues. Such interactions between plants and microorganisms range from parasitic to saprophytic to mutualistic (PorrasAlfaro \& Bayman 2011). For example, fungi present in the soil can colonize seeds and help to break physiological dormancy (Morpeth \& Hall 2000). On the other hand, some decomposer fungi can also degrade tissue of the seed embryo, thereby preventing germination (Fagundes et al. 2011). In addition, endophytic microorganisms can be found

1 Laboratório de Biologia da Conservação, Programa de Pós-graduação em Biodiversidade e Uso dos Recursos Naturais, Universidade Estadual de Montes Claros, 39401-089, Montes Claros, MG, Brazil

2 Laboratório de Ecologia de Microrganismos e Microbiologia ambiental, Programa de Pós-graduação em Biodiversidade e Uso dos Recursos

Naturais, Universidade Estadual de Montes Claros, 39401-089, Montes Claros, MG, Brazil

* Corresponding author: eliogomesfernandes@hotmail.com 
within seeds where they produce or induce the production of primary or secondary metabolites that increase seed germinability (Stone et al. 2000; Pereira et al. 2014). The transmission of endophytic microorganisms may occur vertically or horizontally, and thus a species of plant can be classified according to the mode of transmission of endophytic fungi (Rodriguez et al. 2009).

Copaifera oblongifolia Mart. (Fabaceae), popularly named "Pau d'olinho" is a heliophytic tropical shrub that reaches up to $2.5 \mathrm{~m}$ in height in the Brazilian Cerrado. The shrubs are semideciduous, with the production of new leaves from July to September. Flowering occurs from February to May, and fruits ripen from August to October (Veloso et al. 2017). Upon opening, each fruit exposes one ellipsoid seed (rarely two), which is black, shiny and partially covered by a yellow-orange aril. The species occurs in open areas such as abandoned pastures and borders of Cerrado fragments and highways. Moreover, this shrub often invades pastures and agricultural systems, where it can become dominant and inhibit the development of cultivated plants, especially in northern Minas Gerais State, Brazil (Veloso et al. 2017). The aims of the present study were to identify the fungal community (endophytic and nonendophytic fungi) associated with C. oblongifolia seeds, and to test the effects of these different fungal species on germination.

Mature seeds were collected from 20 adult shrubs of Copaifera oblongifolia in an area of Cerrado vegetation (16 $17^{\prime} 20^{\prime \prime} \mathrm{S} 44^{\circ} 09^{\prime} 02^{\prime \prime} \mathrm{W}$ ) in the municipality of Mirabela, northern Minas Gerais State, Brazil, during October 2015 (period of peak seed dispersal). The region has a semi-arid climate with well-defined dry and wet seasons. The average annual temperature is $23^{\circ} \mathrm{C}$, while the average annual rainfall is about $1000 \mathrm{~mm}$. A total of 50 well-formed seeds (malformed seeds and those with visual signals of attack by predators or pathogens were eliminated) were haphazardly collected from each individual tree and packed in specific paper bags for use in three experimental designs described below.

Experiment 1 evaluated whether superficial asepsis of seeds with alcohol and hypochlorite affect seed germination of $C$. oblongifolia. Thus, a total of 60 seeds were separated into two treatments of 30 seeds each. In the first treatment (asepsis), 30 seeds were laid in $70 \%$ ethanol solution for $1 \mathrm{~min}$ and then immersed in $3 \%$ hypochlorite solution $(\mathrm{NaOCl})$ for $2 \mathrm{~min}$ and followed by washing in sterile distilled water for $1 \mathrm{~min}$. In the second treatment (control), 30 seeds did not receive any asepsis treatment (including washing with sterile distilled water). Seeds of both treatments were then individually sown in a germination tray comprising 60 cells ( $2 \times 2 \mathrm{~cm}$ and $3 \mathrm{~cm}$ high), with sterilized vermiculite as substrate, for seed germination. The germination tray was placed in a germination chamber (BOD) with controlled temperature, luminosity and photoperiod $\left(12 \mathrm{~h}\right.$ light at $28^{\circ} \mathrm{C}$ and $12 \mathrm{~h}$ dark at $25^{\circ} \mathrm{C}$ ). The seeds were irrigated daily with
$3 \mathrm{ml}$ of sterile mineral water and individually inspected to record the date of germination; protrusion of embryo roots was used as a criterion for germination.

Generalized linear models (GLM) were constructed in order to evaluate the effects of superficial asepsis treatment on the time required for germination and the germination percentage. Time required for seed germination and germination percentage were used as response variables and treatment was the explanatory variable. Because seed germination data are binary $(1=$ germinated, $0=$ not germinated) we used a binomial error distribution (corrected for quasibinomial) in model construction. Both models were submitted to residual analysis to check for model fit and suitability of error distribution for each response variable (Crawley 2007). Finally, the models were tested by analyses of variance (ANOVA). All analyses were carried out in R ( $R$ Core Team 2018).

In Experiment 2 a total of 600 seeds were surface disinfected, according to the protocol described above (see Experiment 1), and grouped into five treatments. Each treatment consisted of immersion for 1 second in a 108 spore/mL solution with one of the four fungal taxa and a control: $\mathrm{t} 1=$ Aspergillus niger; $\mathrm{t} 2=$ Aspergillus flavus; $\mathrm{t} 3=$ Mucor sp.; $\mathrm{t} 4=$ Rhizopus stolonifer; and $\mathrm{t} 5=$ control with immersion in sterile distilled water. The fungal taxa were previously isolated from decomposing C. oblongifolia seeds and identified by morphological characters (Barnett \& Barry 1998). After isolation and identification, the fungi were deposited in the fungus collection of the Laboratorio de Ecologia de Microrganismos e Microbiologia Ambiental (Universidade Estadual de Montes Claros - Brazil) with number of accession: D1K-Aspergillus niger; D2K-Aspergillus flavus; D3K - Mucor sp and D4K - Rhizopus stolonifer. The 120 seeds of each treatment were subsequently divided into 12 replicates of 10 seeds each. Finally, each group of 10 seeds was sown in sterile Gerbox boxes, containing sterilized vermiculite as a substrate, until seed germination. The conditions for seed germination were the same as those used in Experiment 1.

Generalized linear models (GLM) were constructed and later tested with ANOVA to evaluate the effects of the treatments on the time required for seed germination and germination percentage. Thus, mean time required for seed germination and germination percentage were used as responses variables and treatment was the explanatory variable. Both models were submitted to residual analysis to check for model fit and suitability of error distribution for each response variable. All analyses were carried out in R (R Core Team 2018).

Lastly, Experiment 3 employed the extinction technique (Fernandes et al. 2015) in order to evaluate the presence of endophytic fungi associated with seeds of $C$. oblongifolia. A total of 30 seeds were selected at random and washed to remove soil residue and dust, followed by disinfection by soaking in $70 \%$ ethanol for $1 \mathrm{~min}$ followed by $3 \%$ sodium 
hypochlorite $(\mathrm{NaOCl})$ for $2 \mathrm{~min}$. After rinsing with sterile distilled water for $1 \mathrm{~min}$, the seeds were pressed on potato dextrose agar (PDA-Himedia) culture medium for 5 seconds to assess the efficacy of surface disinfection. Samples that did not incur any growth on the culture medium after 10 days (photoperiod of 12 hours, $27^{\circ} \mathrm{C}$ ) were considered surface-sterile and used for the isolation of endophytic fungi.

For isolation of endophytic fungi, the disinfected seeds were placed in a $0.85 \% \mathrm{NaCl}$ solution ( $\mathrm{w} / \mathrm{v}$ ) and homogenized in a blender for $60 \mathrm{sec}$. The resulting suspension was filtered through $500 \mu \mathrm{m}$ and $106 \mu \mathrm{m}$ sterile sieves. The seed pieces retained on the 106- $\mu \mathrm{m}$ sieve were collected and added to a test tube containing $30 \mathrm{~mL} 0.85 \%$ saline solution. Next, 300 $\mu \mathrm{L}$ of the supernatant was plated onto PDA, and 15 Petri dishes with culture medium were established. The culture medium was supplemented with $50-\mathrm{mg} / \mathrm{L}$ ampicillin to avoid isolating endophytic bacteria. Next, the Petri dishes were placed in a growth chamber with a photoperiod of 12 hours at $27^{\circ} \mathrm{C}$ for 10 days.

Experiment 1 found that $C$. oblongifolia seeds began germinating on the fourth day after sowing and continued germinating until the 20th day. The seed germination percentage reached approximately $85 \%$ (average $=0.85$, $\mathrm{SE}=0.05$ ). The time required for seed germination (Deviance $=3.450, \mathrm{~F}=0.067, \mathrm{P}=0.796)$ and germination percentage (Deviance $=0.131, \mathrm{~F}=0.126, \mathrm{P}=0.236$ ) did not differ between the control and the asepsis treatment. Therefore, superficial asepsis did not affect seed germinability of $C$. oblongifolia.

The results of Experiment 2 revealed that seed germination of $C$. oblongifolia began on the sixth day after sowing and lasted until the 19th day (Fig. 1A). The germination percentage varied among the treatments (Deviance $=868, \mathrm{~F}=2.690, \mathrm{P}=0.041$ ), with the contrast analysis showing that seeds inoculated with $A$. flavus had a lower germination percentage (Fig. 1B). However, the time required for seed germination did not vary among the different fungal infestation treatments (Deviance $=4.141$, $\mathrm{F}=0.569, \mathrm{P}=0.686$ ).

The results of Experiment 3 revealed that external asepsis of seeds was satisfactory because there was no fungal growth in the tests of culture medium impregnation with the outer surface of seeds. However, attempts to isolate endophytic fungi resulted in no fungal growth in any of the Petri dishes, thereby demonstrating that this plant species does not vertically transmit endophytic fungi.

Previous studies have shown that $C$. oblongifolia seeds have a high germination percentage, and the time required to germination can vary from 12 to 81 days (Veloso et al. 2017). The results of Experiment 1 showed that $C$. oblongifolia seeds do indeed have a high germination percentage (approximately 85\%) and that asepsis does not affect seed germinability. However, the majority of seeds germinated from 6 to 15 days after being sown. Others studies developed with plant species of the genus Copaifera (e.g., Fagundes et al. 2013; Souza et al. 2015) suggest that traits, such as seed size and age, can affect the time required for seed germination. This indicates that it is probable that factors intrinsic to the seeds used in the experiment are affecting the velocity of seed germination.

The fungi tested in the present study (A. niger; A. flavus; Mucor sp.; R. stolonifer) occur naturally in C. oblongifolia seeds, and are known to play an important role as decomposers in natural environments (Alexopoulos et al. 1996; Webster $\&$ Weber 2007). In spite of the occurrence of decomposer fungi on seeds of several plant species, the influence of these microorganisms on germinability varies among species and environmental conditions. Among the decomposer fungi tested in the present study, only A. flavus had a negative effect on the germination percentage of $C$. oblongifolia.
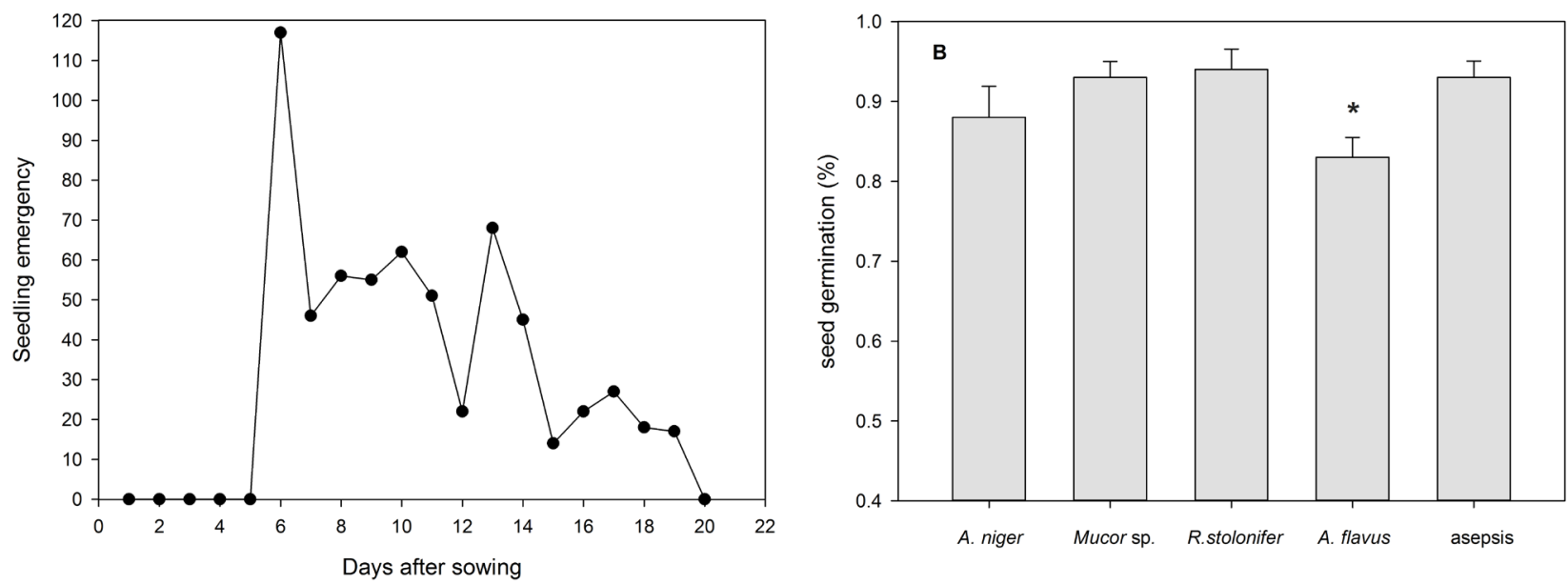

Figure 1. Effects of treatments of spores infestations on $(\mathbf{A})$ seedling emergence over the first 20 days after sowing and (B) percentage of seed germination of Copaifera oblongifolia. Asterisk represents significant difference among treatments $(\mathrm{P}<0.05)$. 
Aspergillus flavus is a saprophytic soil fungus that produces the carcinogenic secondary metabolite aflatoxin, and infects and contaminates pre-harvest and post-harvest seed crops (Amaike \& Keller 2011). Thus, further research aimed at evaluating the effect of this fungus on seed germination is still needed.

The results of Experiment 3 indicate that Copaifera oblongifolia does not possess endophytic fungi in its seeds. Plant-endophytic fungus interactions can be classified into four classes according to mode of transmission, colonized host, type of colonization, variation in colonized hosts and host species richness (Rodriguez et al. 2009). The first class (Class 1 ) is represented by clavicipitaceous endophytic fungi that have vertical and horizontal transmission and are specific to grasses. The second class (Class 2) consists of endophytic fungi that have vertical and horizontal transmission and includes a greater diversity of species, with the majority belonging to the phylum Ascomycota and the minority to the phylum Basidiomycota. The fungi of Class 3 are dispersed only through horizontal transmission, are exclusively found colonizing tissues above the level of the soil and are not necessarily host-specific. Finally, endophytic fungi of Class 4 (also called pseudomycorrhizal fungi), are transmitted horizontally, have dark pigmentation and are found associated with terrestrial plant roots. Therefore, we can classify $C$. oblongifolia as belonging to Class 3 , since endophytic fungi were not present in their seeds, but may be exclusively horizontally transmitted.

\section{Acknowledgements}

The authors would like to thank the trainees of the Laboratório de Biologia da Conservação of Unimontes for their support during field and laboratorial work. The authors also thank the Pos-graduate Program of Biodiversity (PPG-BURN) of Unimontes for all logistical support. The authors also thank CNPq, CAPES and FAPEMIG for financial support in the form of grants received.

\section{References}

Alexopoulos CJ, Mims CW, Blackwell M. 1996. Introductory mycology. New York, John Wiley \& Sons.

Amaike S, Keller NP. 2011. Aspergillus flavus. Annual Review of Phytopathology 49: 107-133.

Barnett HL, Hunter BB. 1998. Illustrated genera of imperfect fungi. 4th edn. Saint Paul, Burges Publishing Company.

Crawley MJ. 2007. The R Book. London, John Wiley \& Sons.

Fagundes M, Costa FV, Antunes SF, et al. 2013. The role of historical and ecological factors on initial survival of Copaifera langsdorffii Desf. (Fabaceae). Acta Botanica Brasilica 27: 480-487.

Fagundes M, Camargos MG, Costa FV. 2011. A qualidade do solo afeta a germinação das sementes e o desenvolvimento das plântulas de Dimorphandra mollis Benth. (Leguminosae: Mimosoidae). Acta Botanica Brasilica 25: 908-915.

Fernandes EG, Pereira OL, Silva CC, Bento CBP, Queiroz MV. 2015. Diversity of endophytic fungi in Glycine max. Microbiological Research 181: 84-92.

Harper JL. 1977. Population biology of plants. London, Academic Press. Metivier JR. 1986. Dormência e germinação. In: Ferrik MG. (ed.) Fisiologia vegetal. São Paulo, EPU. p. 343-392.

Morpeth DR, Hall AM. 2000. Microbial enhancement of seed germination in Rosa corymbifera 'Laxa'. Seed Science Research 10: 489-494.

Pereira AC, Fonseca FS, Mota GR, et al. 2014. Ecological interactions shape the dynamics of seed predation in Acrocomia aculeata (Arecaceae). PLOS ONE 9: e98026. doi:10.1371/journal.pone.0098026

Porras-Alfaro A, Bayman P. 2011. Hidden fungi, emergent properties: endophytes and microbiomes. Annual Review of Phytopathology 49: 291-315.

R Core Team. 2018. R: A language and environment for statistical computing. Vienna, R Foundation for Statistical Computing. https:// www.R-project.org/

Rodriguez RJ, White JF, Arnold AE, Redman RS. 2009. Fungal endophytes: diversity and functional roles. New Phytologist 182: 314-330.

Souza ML, Fagundes M. 2014. Seed size as key factor in germination and seedling development of Copaifera langsdorffii (Fabaceae). American Journal of Plant Sciences 5: 2566-2573.

Souza ML, Silva DP, Fantecelle LB, Lemos Filho JP. 2015. Key factors affecting seed germination of Copaifera langsdorffii, a Neotropical tree. Acta Botanica Brasilica 29: 473-477.

Stone JK, Bacon CW, White JF. 2000. An overview of endophytic microbes: endophytism defined. In: Bacon CW, White JF. (eds.) Microbial endophytes. New York, Marcel Dekker. p. 3-30.

Veloso CR, Silva PS, Siqueira WK, et al. 2017. Intraspecific variation in seed size and light intensity affect seed germination and initial seedling growth of a tropical shrub. Acta Botanica Brasilica 31: 736-741.

Webster J, Weber RWS. 2007. Introduction to Fungi. New York, Cambridge University Press. 